\title{
Evaluated Nuclear Structure Data File A Manual for Preparation of Data Sets
}

\author{
W. Bruce Ewbank \\ Marcel R. Schmorak
}

MASTER 
Contract No. W-?:405-eng-26

Nuclear Data Project

EVALUATEd NUCLEAR STRUCTURE DATA FILE

A MANUAL FOR PREPARATION OF DATA SETS

W. Bruce Ewbank and Marcel R. Schmorak

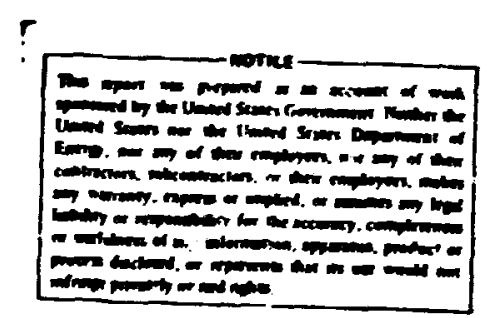

February 1978

OAK RIDGE NATIONAL LABORATORY

Oak Ridge, Tennescee 37830

operated by

UNION CARBIDE CORPORATION

for the

DEPARTMENT OF ENERGY 
CONTENTS

I. INTRODUCTION ................... I

I. GENERAL STRUCTURE OF THE DATA FILE ...... 2

III. STANDARD ONE-CARD RECORD FORMATS ..... 3
A. Introduction
B. The Standard One-Cand Recond Formats
C. Comment Records
D. Summary

IV. RECORDS CONTAINING MORE THAN ONE CARD ... IS
A. Card Enumeration
B. Formats for Continuation Cards
C. Comment Continuation

v. DETAILED FIELD DESCRIPTIONS .......... 16
A. NUCID
B. DSID
C. DSREF
D. RTYPE

V. UNCERTAINTIES ................... I9

A. Standard Numeric Uncertainties

B. Non-numeric Uncertainties

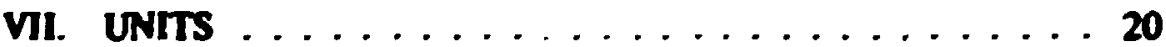

VIII. FREE-FORM FIELDS $\ldots \ldots \ldots \ldots \ldots \ldots$

APPENDIX 1: PREPARING FORMAT RECORDS . . . . 23

APPENDIX 2: COMPUTER PROGRAMS . . . . . . . . 27

APPENDIX 3: SAMPLE DATA SET INPUT/OUTPUT . . . . 31

APPENDIX 4: NDSLIST TRANSLATION DICTIONARY . . . 35 


\title{
EVALUATEd NUCLEAR STRUCTURE DATA FILE
}

A MANUAL FOR FREPARATION OF DATA SETS

\author{
W. Bruce Ewbank and Mareel R. Schmorak
}

\section{INTRODUCTION}

The Nuctear Data Project at ORNL is continuing to expand its computer-based file of nuclear structure data, which is intended for use by both basic and applied users. For every nucleus, the Evaluated Nuclear Structure Data File (ENSDF) contains evaluated nuclear structure in:iormation. For masses $A>45$, this information is documented in the Nuclear Date Sheets: for A $<45$, ENSDF is based on compilations published in the joumal Nuclear Physics. In addition, the file will incorporate such important new data as may hre become available since the most recent published evaluation. It is hoped that nuclear structure research workers will pasticipate in building the data file by preporisg their new data in such a form that it can easily be included. It is desired that the data file represent the best currently available nuclear structure data.

This manual describes a standard input format for nuclear structure iata. The format is sufficiently structured that bulk data can be entered efficiently. At the same time, the structure is open-ended and can accommodate most measurad nr deduced quantitites that yield nuclear structure information.

The data file is used by both basic and applied scientists and engineers. The stuclear Data Project is using the dita file to prepare Nuclear Data Sheets, collections of specific nuclear properties and of particular typer of experimental information. Computer programs have been developed at the Data Project to perform consistency checking and routine calculations. Programs are also used for preparing level srheine drawings and for reformatting the nuclear structure data for special tabular presentation. Data extracted from the Evaluated Nuclear Structure Data File is also used by the Data Project to respond to specific requests from the nuclear community for current nuclear structure information. 


\section{H. GENERAL STRUCTURE OF THE DATA FILE}

\section{A. Introduction}

The Evaluated Nuclear Structure Data File (ENSDF) is made up from a collection oi "data sets", each of which describes the results of a single experiment or the combined evaluated results of a number of experiments of the same type. The appearance of these data sets within the computer file is of less concern here than is the appearance of the data sets either before they enter the computer or aiter they hrve been retrieved. The Nuclear Data Project has designed a card-based (or card-imaga-based) external representation of results of a nuclear structure experinert, which may be used for preparing input to the computer file. In the remainder of this manual, we shall refer to the group of cards or card images as a data set, even though it is understood to be only an extemal version of the internal data set which makex up part of the data Fil. A sample data set is given in Appendix 3.

\section{B. Summary of Dare Set Sinucture}

A data set is composed of records; each record is made up of one or more card images.

A data set must begin with an IDENTIFICATION record (with label information) and must end with an END record (a blank card). Between these two records, there will be as many additional records as are needed to describe fully the experiment or the evaluated data set.

Immediately following the IDENTIFICATION record is a group of records which contain information about the entire data set. The NORMALIZATION (N), Q-VALUE (Q), FORMAT (F), PARENT (P), and general COMMENT (C) records are of this type.

The body of a data set is composed of numeric data records which describe the measured or deduced properties of levels, $\gamma$ mys, a particles, etc. These records are anociated with the level which decays (for GAMMA records) or the level which is populated (for B-, EC, or ALPHA records). Thus, each LEVEL record is followed by a group of records describing charged-particle decay into the kevel and $\boldsymbol{\gamma}$-ray decay out of the level.

If a GAMMA record (or ALPHA or B+ or B-) properly belongs in a data set, but it cannot be asociated with any particular level, then the record should be placed in the data set before any LEVEL records.

The placement of COMMENT records is described in Section III.C. 


\section{iI. Standard ONE-CaRd RECORD fOAMATS}

\section{A. Introctuction}

In most cases, all information for a record can be placed on a sinje 80-columa card. A "standard" format has been defined for each one-card record, such that the most commonly used quantitites can be placed on a sinde cand. The standard formats are decribed in this section for each record. If a needed quantity is not included in the siandard format or if a velue will not fit within the fold defined for the value by the standard format, then a FORMAT record will be required (see Appendix I). If a record cannot be contrined on a single card, then additional cards can be prepared as described in Section IV (for examples, see Appendix 3).

\section{B. The Stondard One-Card Record Formats}

Record formats are given below in the same order in which they would nomally be encountered in a data set. Conditions under which each record may appear or be required are given in parentheses. The format descriptions give the felds (in inchusive card-column numbers). the field names (the formal "name" of the quantity that soes into the field), and a brief field description. Card columns not explicitly included in the falds are expected to be blank. Additional information about each freld can be found in the reference section noted. (Any numerical field left blank usually implies that the numerical information is lacking. Numbers will usually be assumed to be positive ualless stated otherwise.) Numbers can be entered anywhere in the appropriate field (i.e., there is no need to left-edjust or right-adjust.) 


\section{THE IDENTIFICATION RECORD}

(Required for all dete sets.)

\begin{tabular}{|c|c|c|c|c|}
\hline Field & & Nane & Description & Reference \\
\hline Cal & $\begin{array}{c}1-5 \\
8\end{array}$ & NUCTD & $\begin{array}{l}\text { Nucleus identification } \\
\text { Must be that }\end{array}$ & V.A \\
\hline & $10-39$ & DSID & Dote set identification & V.B \\
\hline & $40-64$ & MSREF & Data set references & V.C \\
\hline & $75-00$ & DATE & $\begin{array}{l}\text { The date (year/nomith/day) when the data } \\
\text { set was placed in the data file (entered } \\
\text { automatically by computer) }\end{array}$ & \\
\hline
\end{tabular}

2. THE FORMAT RECORD

(Required ondy if the standerd format is mol used. See Appendix I.)

\begin{tabular}{|c|c|c|c|}
\hline Fidd & Nare & Description & Referenc \\
\hline $1-5$ & NUCID & Nucleus identification & V.A \\
\hline 7 & $\mathbf{F}$ & Letter " $F "$ is required & \\
\hline 8 & RTYPE & Record type being formatted & V.D \\
\hline $10-80$ & FORMATS & $\begin{array}{l}\text { A complete description of the format for } \\
\text { reconds of type RTYPE; e.E. } E=10 \text {. } \\
D E=19 . J=24, \ldots \text { SYM =COL, where } \\
\text { SYM is any data type (DTYPE) allowed } \\
\text { for RTYPE records and COL is the cot } \\
\text { umn on RTYPE cards where the value } \\
\text { of SYM begins }\end{array}$ & \\
\hline
\end{tabular}




\section{THE COMMENT RECORD}

(See Section III.C and Apperdix 3.)

General Comments

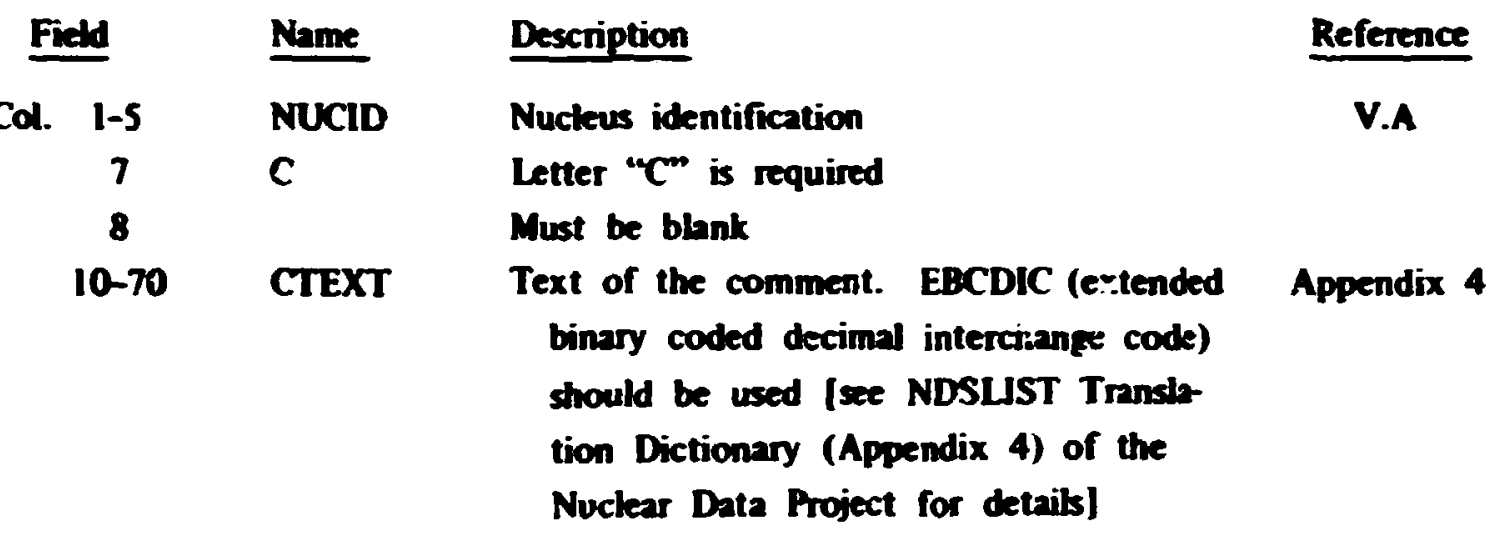

Record Comments and Flaged Comments

\begin{tabular}{|c|c|c|c|}
\hline Field & Name & Description & Reference \\
\hline $1-5$ & NUCID & Nucleus identification & V.A \\
\hline 7 & C & Letter "C" is required & \\
\hline 8 & RTYPE & Record type being commented upon & V.D \\
\hline $10-19$ & SYM(FLAG) & $\begin{array}{l}\text { SYM = type of data being commented } \\
\text { upon }\end{array}$ & $\begin{array}{l}\text { Appendix 1, } \\
\text { Section C }\end{array}$ \\
\hline & & $\begin{array}{l}\text { FLAG = character in col. } 77 \text { of all records } \\
\text { to which the comment applies. If FLAG } \\
\text { is omitted, the comment is understood to } \\
\text { apply to all records of RTYPE }\end{array}$ & \\
\hline $20-70$ & CTEXT & $\begin{array}{l}\text { Text of comment (same as for general cr.n- } \\
\text { ments). In cases where continuation cards } \\
\text { are not used, the CTEXT may extend ro } \\
\text { col. } 80 \text {. On continuation comment records, } \\
\text { cols. } 10-70 \text { may be used for CTEXT, and } \\
\text { SYM(FLAG) is not repeated }\end{array}$ & \\
\hline
\end{tabular}


4. THE NORMALIZATION RECORD

(Required if an ebsolute normalization is possible: used mainly with decay data sets.)

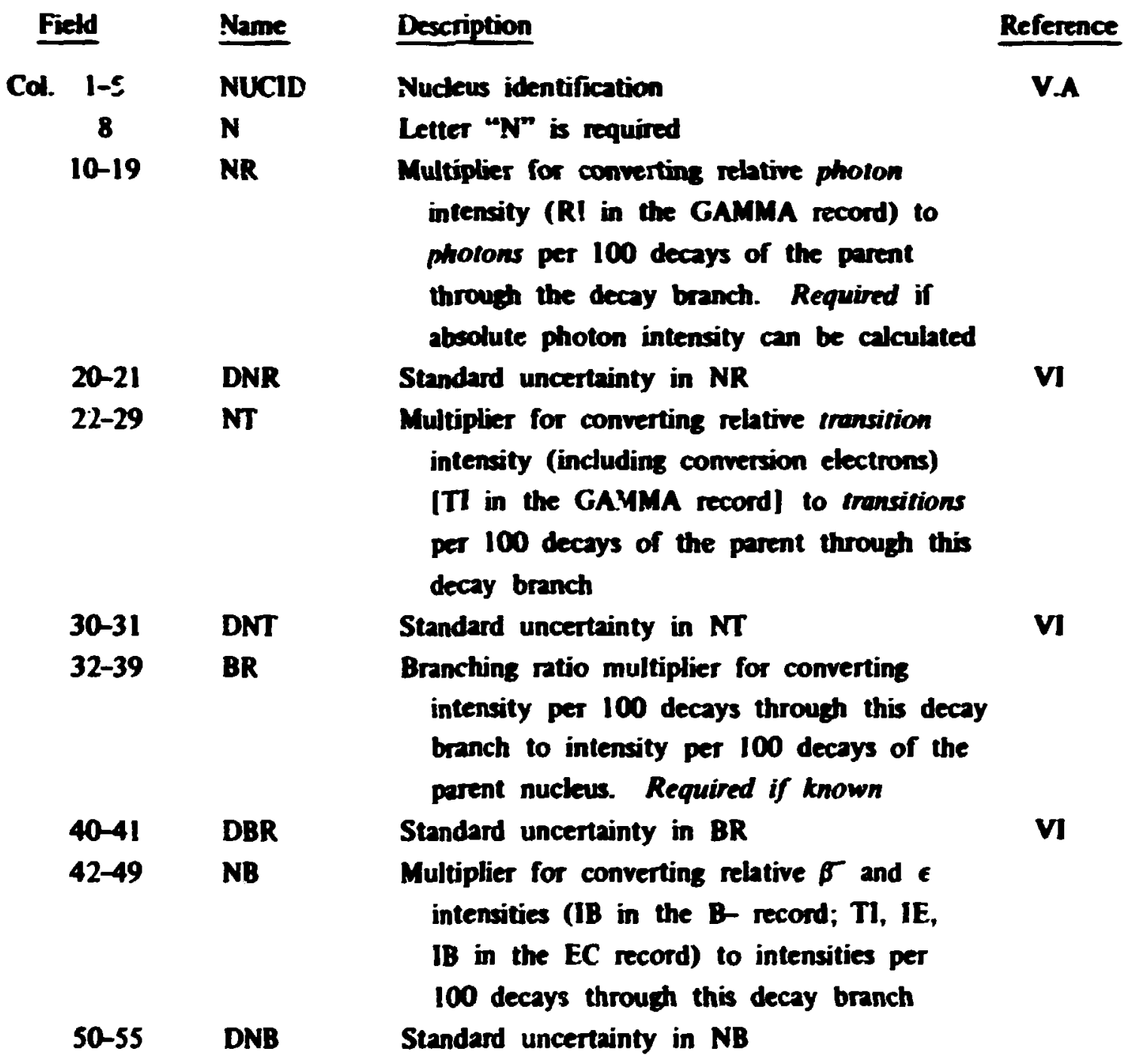




\section{THE PARENT RECORD}

(Required for all decay dase sets. except IT decay.)

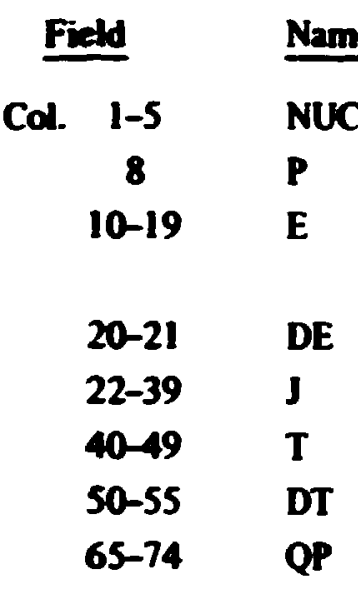

Description

Reference

Nuckeus identification for parent record

V.A

Letter "p" is required

Energy of the decaying level in keV

(0 for zs)

Standard uncertainty in E

VI

Spin and parity

Half-life; units must be given VII

Standard uncertainty in $T$

V1

Ground-state Q-value in keV (total energy available for g-s. $\rightarrow$ g.s. transition); will always be a positive number

75-76 DQP

Standard uncertainty in QP

VI

6. THE Q-VALUE RECORD

(Required for adopted levels data sets.

If signs are not given. they will be assumed to be + .)

\begin{tabular}{|c|c|c|}
\hline Field & Name & Description \\
\hline $1-5$ & NUCID & Nucleus identification \\
\hline 8 & $\mathbf{Q}$ & Letter "Q" is required \\
\hline $10-19$ & $Q^{-}$ & $\begin{array}{l}\text { Total energy (keV) available for } \beta \text { decay } \\
\text { of the ground state. (Q }\left(Q^{-}>0 \text { if } \beta\right. \\
\text { decay is energetically possible) }\end{array}$ \\
\hline $20-21$ & $\mathbf{D Q}^{-}$ & Standard uncertainty in $Q^{-}$ \\
\hline $22-29$ & SN & Neutron separation energy in keV \\
\hline $30-31$ & DSN & Standard uncertainty in SN \\
\hline 32-39 & SP & Proton separation energy in keV \\
\hline $40-41$ & DSP & Standard uncertainty in SP \\
\hline $42-49$ & QA & $\begin{array}{l}\text { Total energy }(\mathrm{k} \cdot \mathrm{V}) \text { available for a decay } \\
\text { of the ground state }\end{array}$ \\
\hline $50-55$ & DQA & Standard uncertainty in QA \\
\hline $56-80$ & REF & Reference citation(s) for the Q-values \\
\hline
\end{tabular}

Reference

V.A

VI

VI

VI

VI 
7. THE LEVEL RECORD

(Optiond, dihough a data set usually has et lest one.)

\begin{tabular}{|c|c|c|c|}
\hline Fich & Name & Description & Reference \\
\hline $1-5$ & NUCTD & Nuckeus identification & $\mathbf{V . A}$ \\
\hline 8 & $\mathbf{L}$ & Letter " ${ }^{\prime \prime}$ is required & \\
\hline $10-19$ & $\mathbf{E}$ & Level energy in keV & \\
\hline $20-21$ & DE & Standard uncertainty in $E$ & VI \\
\hline $22-39$ & $\mathbf{J}$ & Spin and parity & \\
\hline $40-49$ & $\mathbf{T}$ & $\begin{array}{l}\text { Half-life of the level: units must be given. } \\
\text { Mean-life expressed as width of level, in } \\
\text { units of energy, may also be used }\end{array}$ & VII.A \\
\hline $50-55$ & DT & Standard uncertainty in $T$ & $\mathbf{V I}$ \\
\hline $56-64$ & $\mathbf{L}$ & $\begin{array}{l}\text { Angular momentum transfer in the reaction } \\
\text { determining the data set. (Whether it } \\
\text { is } \mathbf{L}_{n}, \mathbf{L}_{p}, \Delta L \text {, etc., is determined from } \\
\text { the DSID field of the IDENTIFICATION } \\
\text { record.) }\end{array}$ & \\
\hline $65-74$ & $\mathbf{S}$ & $\begin{array}{l}\text { Spectroscopic strength for this level as deter- } \\
\text { mined from the reaction in the IDENTI- } \\
\text { fication reccrd. (Spectroscopic factor for } \\
\text { particle-exchange reactions; } \beta \text { for inelastic } \\
\text { scattering) }\end{array}$ & \\
\hline $75-76$ & DS & Standard uncertainty in S & \\
\hline 77 & C & $\begin{array}{l}\text { Comment FLAG (see Section III.C.3) used } \\
\text { to refer to a particular comment record }\end{array}$ & \\
\hline $78-79$ & MS & $\begin{array}{l}\text { Metastable state is denoted by } M \text { or } M I \text { for } \\
\text { the first isomer; } M 2 \text {, for the second, etc. }\end{array}$ & \\
\hline 80 & $\mathbf{Q}$ & $\begin{array}{l}\text { The character "op" denotes an uncertain or } \\
\text { questionable level }\end{array}$ & \\
\hline & & $\begin{array}{l}\text { Letter " } \mathrm{g} \text { " denotes neutron or proton } \\
\text { separation energy }\end{array}$ & \\
\hline
\end{tabular}




\section{THE GAMMA RECORD}

(Must follow the LEVEI. recond for the krel from which the I may derays Record for $y$ rays which are unassizned in a level scherme should prerede the first terel of the date set.)

\section{Fiebl}

Col. 1-5

$\begin{array}{cl}8 & \text { G } \\ 10-19 & \text { E } \\ 20-21 & \text { DE } \\ 22-29 & \text { RI } \\ 30-31 & \text { DRI } \\ 32-41 & \text { M } \\ 42-49 & \text { MR }\end{array}$

50-55

56-62

63-64

$65-74$

$75-76$

77

78

79

80
ORG

END

Name

NUCID

DE

DRI

MR

DMR

CC

DCC

TI

DTI

C

END

$\mathbf{Q}$
Description

Nucleus identification

Letter " $G$ " is required

Enersy of the pray photon in keV

Srandard uncertainty in E

Relative photon intersityt

Standard uncertainty in RI

Multipolarity of trassition

Mixing ratio. $\delta$. (Sign must be shown explicitly if known If no sien is given. it will be assumed to be unknown.)

Standard uncertainty in MR

vi

Total conversion coefricient

Standard uncertainty in CC

Relative total transition intensityt

Standard uncertainty in TI

VI

vi

v
Referemace

V.A

Comment FLAG (see Section III.C.3. "Flayed Comments") used to refer to a particular comment record. The character * denoles a multiply placed $\boldsymbol{\gamma}$ ray

Letter "C" denoted coincidence with a preceding radiation

Letter " $\mathrm{C}$ " denotes coincidence with a forlowing radiation

The character "?" denotes an uncertain placement of the transition in the level scheme

Letter " $S$ " denotes an expected. but as yet unobserved. transition

†The intencity units are defined by the NORMALZaTION record. 


\section{THE $\beta$ S RECORD}

(Must follow the LEVEL recora for the level which is fed by the F.)

\begin{tabular}{|c|c|c|c|}
\hline Field & Name & Description & Refereng \\
\hline $1-5$ & NUCIn & Nucleus identification & V.A \\
\hline 8 & $\mathbf{B}$ & Letter " $B$ " is required & \\
\hline $10-19$ & $\mathbf{E}$ & $\begin{array}{l}\text { Endpoint enersy of the } \sigma \text { in keV only } \\
\text { if measured }\end{array}$ & \\
\hline $20-21$ & DE & Standard uncertainty in $E$ & $\mathbf{V}$ \\
\hline $22-29$ & IB & Intensity of the p-decay branch & \\
\hline $30-31$ & DIB & Standard uncertainty in IB & $\mathbf{n}$ \\
\hline $42-49$ & LOGFT & Los $f$ for the $\sigma$ transition & \\
\hline $50-55$ & DFT & Standard uncertsinty in LOGFT & $\mathbf{V}$ \\
\hline 77 & $\mathbf{C}$ & $\begin{array}{l}\text { Comment FLAG (see Section III.C.3, } \\
\text { "Flazged Comments"). (Letter "C" } \\
\text { denotes coincidence with a following } \\
\text { radiation.) }\end{array}$ & \\
\hline 78-79 & UN & $\begin{array}{l}\text { Uniqueness classification for the } \sigma \text { decay, } \\
\text { e.E., IU, } 2 U \text {. (A blank signifies an } \\
\text { allowed or a nonunique forbidden tran- } \\
\text { sition.) }\end{array}$ & \\
\hline 80 & $\mathbf{Q}$ & $\begin{array}{l}\text { The character "?" denotes an uncertain or } \\
\text { questicnable } \sigma \text { decay } \\
\text { Letter " } S \text { " denotes an expected or predicted } \\
\text { transition }\end{array}$ & \\
\hline
\end{tabular}

10. THE EC (OR EC $\left.+\beta^{+}\right)$RECORD

(Must follow the LEVEL record for the level being populated in the decay.)

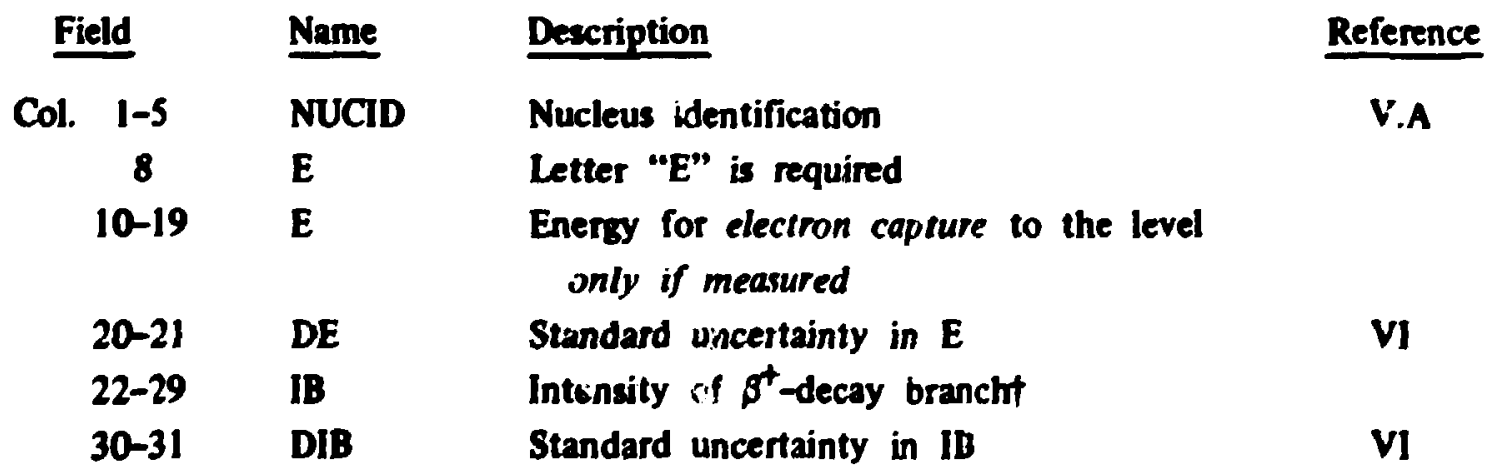


The EC (or EC $+\beta^{+}$) Record

\section{Continued}

\begin{tabular}{|c|c|c|c|}
\hline Field & Name & Description & Reference \\
\hline ol. 32-39 & IE & Intensity of electron capture brancht & \\
\hline $40-41$ & DIE & Standard uncertainty in IE & VI \\
\hline $42-49$ & LOGFT & Log $f\left(\right.$ for $\left(\epsilon+g^{+}\right)$transition & \\
\hline $50-55$ & DFT & Standard uncertainty in L.OGFT & VI \\
\hline $65-74$ & TI & Total $\left(\epsilon+\beta^{+}\right)$decay intensityt & \\
\hline $75-76$ & DTI & Standard uncertainty in TI & V! \\
\hline 77 & $\mathbf{C}$ & $\begin{array}{l}\text { Comment FLAG (sce Section III.C.3, } \\
\text { "Flaged Comments"). (Letter " } C \text { " } \\
\text { denotes coincidence between } \beta^{+} \text {and a } \\
\text { following radiation.) }\end{array}$ & \\
\hline $78-79$ & UN & $\begin{array}{l}\text { Uniqueness classification for } \epsilon, \beta^{+} \text {decay, } \\
\text { e.g., IU. } 2 U \text {. (A blank signifies an } \\
\text { allowed or a nonunique forbidden tran- } \\
\text { sition.) }\end{array}$ & \\
\hline 80 & $\mathbf{Q}$ & $\begin{array}{l}\text { The character "?" denotes an uncertain or } \\
\text { questionable } \epsilon, \beta^{+} \text {branch } \\
\text { Letter " } S \text { " denotes an expected or pre- } \\
\text { dicted transition }\end{array}$ & \\
\hline
\end{tabular}

\section{THE ALPHA RECORD}

(Must follow the LEVEL record for the level being populated in the decay.)

\begin{tabular}{|c|c|c|c|}
\hline Field & Name & Description & Reierence \\
\hline $1-5$ & NUCID & Nucleus identification & V.A \\
\hline 8 & A & Letter " $A$ " is required & \\
\hline $10-19$ & $\mathbf{E}$ & Apha energy in keV & \\
\hline $20-21$ & DE & Standard uncertainty in $E$ & VI \\
\hline $22-29$ & IA & $\begin{array}{l}\text { Intensity of a-decay branch in percent of } \\
\text { the total a decay }\end{array}$ & \\
\hline $30-31$ & DIA & Standard uncertainty in IA & VI \\
\hline
\end{tabular}

HIE, IB, and $\pi$ should be in the same units (see aso NB in NORMALIzATION record). 
The Alpha Record

Conrinued

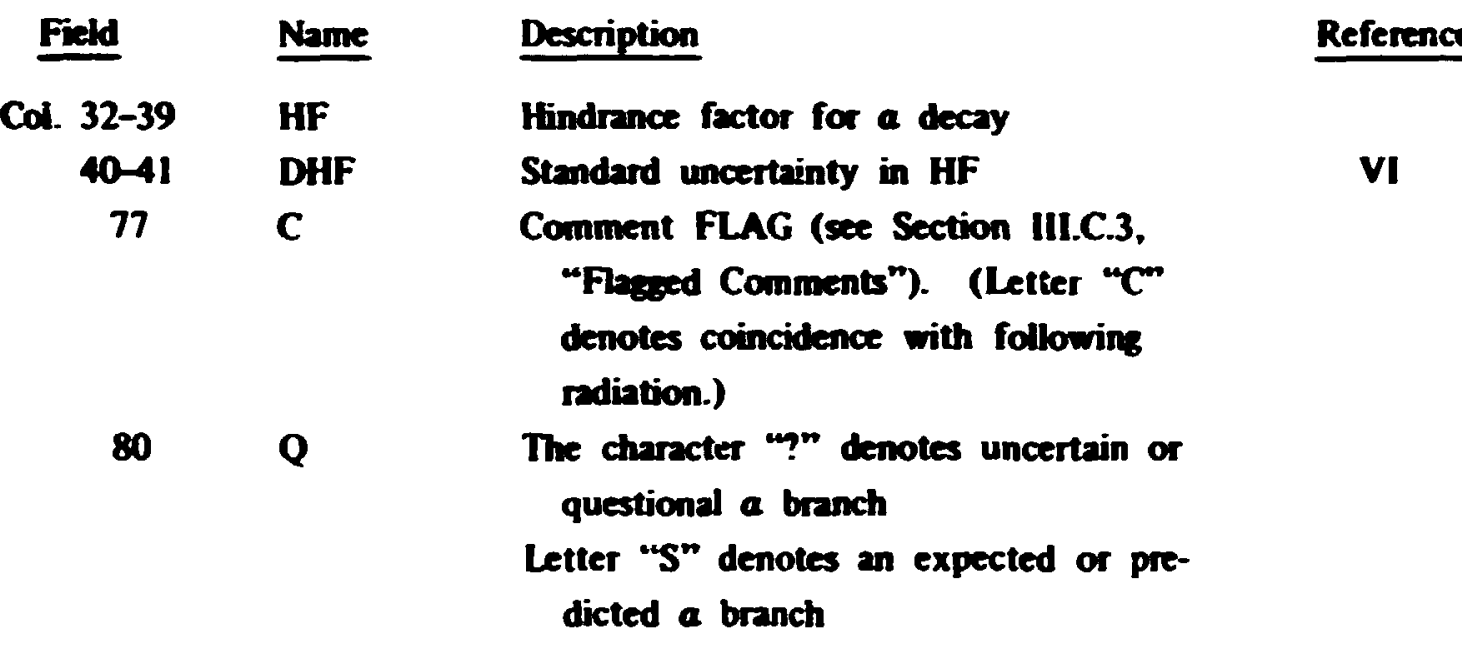

\section{THE END RECORD \\ (Required for all data sets.)}

Field

Dascription

Col. $1-80$

All columns are blank

\section{Comment Records}

Several types of COMMENT records are available. The first cards of COMMENT records are described below.

1. General comment - RTYPE (col. 8) is left blank. The comment refers to the whole data set. (Or in the case that NUCID contains only the mass number, $A$, the comment refers to the whole mass-chain A.) General comments must be placed in a data set before any L, G, B, E, or A. records.

2. Record comment - RTYPE (col. 8) is one of the following: L, G, B, E, A. Columns 10-19 are either a) blank for comments referring to the whole record specified by RTYPE or b) cols. 10-19 specify the comment further (e.g., G in col. 8 and $R I$ in cols. 10-11 define a comment referring to $r$-ray photon intensity). Record com. ments placed at the head of the data set refer to all records of the specified RTYPE in the data set. Record comments placed immediately following a record refer only to that one record. (For example, a comment with $L$ in col. 8 and $T$ in col. 10, 
placed at the head of a data set, refers to all kevel half-lives in that data set. The same comment placed immediarely following the level record for the second-excited state refers only to the hal'-tife of the second-excited state.)

Comments for which RTYPE is N, P. or Q must be pleced immediately followin those records.

3. Flased comment - RTYPE (col. 8) is one of the following: L, G, B, E, A: columas 10-19 contain SYM(FLAG). SYM is the name of the field or a special wond (e.b., BAND) deacribing some common feature of a group of reconds with the same RTYPE. FLAG is a character in col. 77 of all the records in the data set to which the comment applies. Flazed comments must be placed before any L, G, B, E, or A records. The FLAG will consist of one or more different characters enclosed in parentheses. (In general. any EBCDIC charecter may be used for FLAG, except C and - on some records.)

4. Comment continuation - For any COMMENT record, the text of the comment (CTEXT) may be continued on continuation cards starting in col. 10. (For ease of editing and revising comments, it is recommended that CTEXT not extend beyond col. 70.) A string of characters translated as one unit by the NDSLIST Transhation Dictionary (Appendix 4) should not be split between two cards.

D. Summany

The following figure summarizes the standard one-card formats for all allowed record types. 


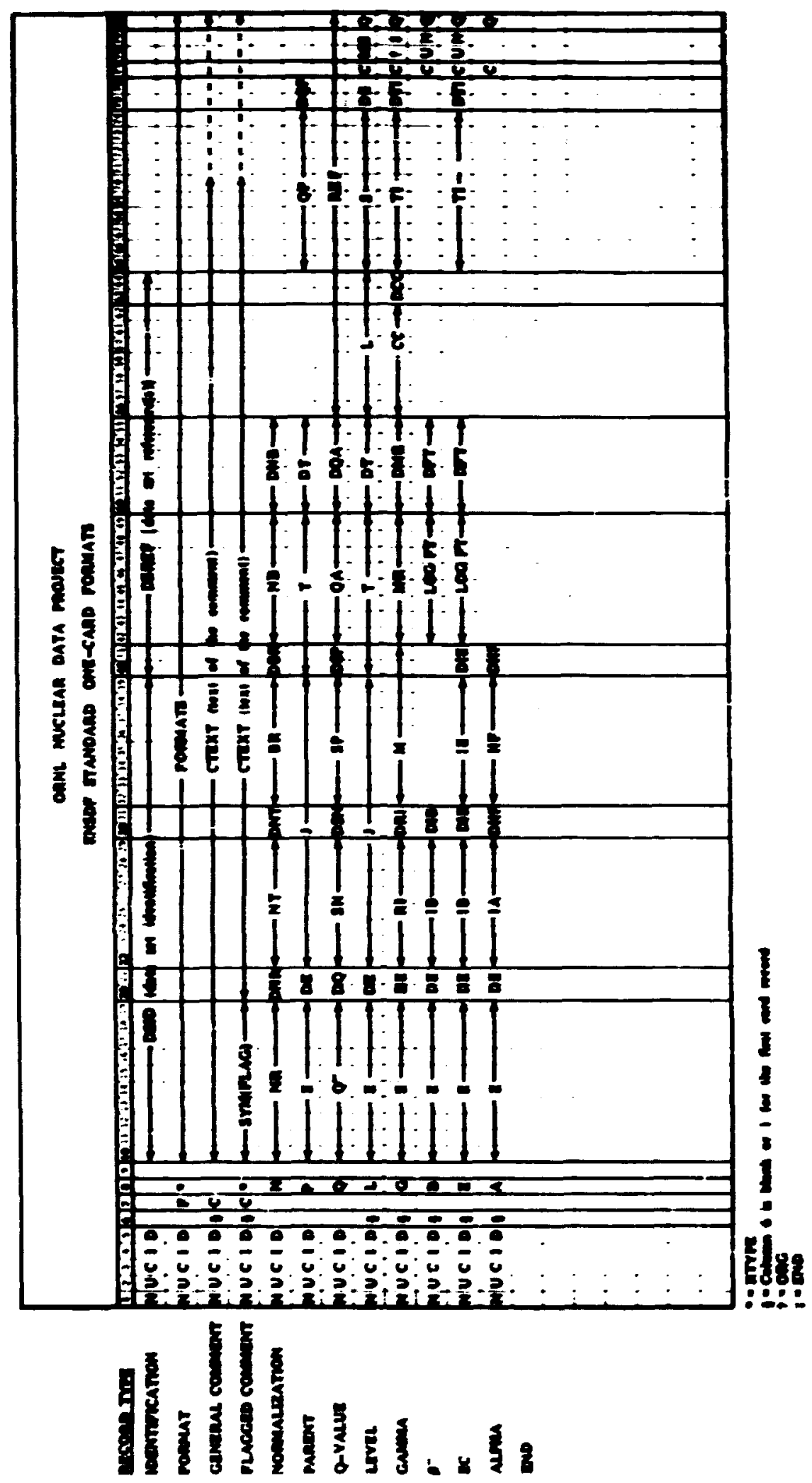




\section{RECORDS CONTAINING MORE THAN ONE CARD}

\section{A. Cord Enameration}

If all the information for a given record type cannot be contained on a single card, thrn it is poovity to use additional cards to describe the record fully. The furst cand of a record will have the number 1 or a blank in col. 6. Subsequent cands will have charecters different frow 1 or blank (usually running numbers: 2, 3, etc., up to 9). It is not allowed to have continuation cands for the IDENTIFICATION record, the FORMAT record, the Q-VALUE recond, the NORMALZATION record, or the END record, since these reconds consist of a single card. (The FORMAT record consiots of a single cand for each recond type for which a special format is described.)

\section{B. Formats for Continuation Cands}

The second, third, etc.. cards of a record do not have a standard format. The data must be presented in free-field format (Section VIII). For example:

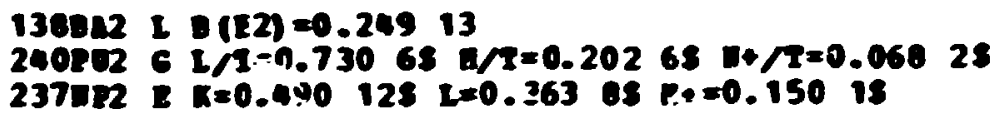

The data types given on continuation cards are limited to the set of names listed under columns DTYPE for each record type in Appendix 1. The data type and the data value may be connected by a relational operator from the following list.

$\begin{array}{ll}\text { EQ or }= & \text { equal to } \\ \text { LE } & \text { less than or equal to }(<) \\ \text { LT or }< & \text { less than } \\ \text { GT or }> & \text { greater than } \\ \text { GE } & \text { greater than or equal to }(\geq) \\ \text { AP } & \text { approximately equal to }(\approx) \\ \text { SY } & \text { obtained from systematics } \\ \text { CA } & \text { calculated value }\end{array}$

The alphabetic representations must contain a blank on either side; i.e., "_G1_". "_AP_".

C. COMMENT Continuation"

See Section III.C. 


\section{DETALED FIELD DESCRITIONS}

\section{A. NUCID}

The standard nucleus identification consists of two to five characters giving the A-ratue and the chemical symbol of a nucleus, e.8., 9B, 20F, 98RU, I77TIF. The mucters identification must be contained within the fidd defined for it (cols 1-5 on most cands). The nucleus identification must be inchuded on every IDENTIFICATION record. It is strongly recommended that it also be included on every cand of a data set except the END record. When a data set is merged onto the data file, the NUCID is moved to a standard position with the inst digit of the A-robe appearing in col. 3 of the NUCCD field. This fiedd is copied automatically onto every card of the data set except the P-record and the END record.) The data set will be handed correctly if all cands except the IDENTIFICATION record contain bianks in the NUCID fredd. Ceneral comments pertaining to the whole A-(mass) chain evaluation contain only the $A$-vahe in the NUCTD field.

B. DSID

The content of a data set is described in a standard way in the DSID field of the IDENTIFICATION record. The standards may be described urder three general headings: 1) decay data sets, 2) reaction data sets, 3) "adopted" data sets.

1. For a data set describing the results of a measurement of radioactive decay, the DSID field contains three parts separated by one or more blanks - the decaying nucleus, the type of decay, and the word "DECAY"; e.g.,

$\begin{array}{llll}\text { 22NA } & \text { B+ } & \text { DECAY } & \\ \text { 64Y } & \text { B- } & \text { DECAY } & \\ \text { 1341 } & \text { IT } & \text { DECAY } & (37 \mathrm{M}) \\ 1341 & \text { B- } & \text { DECAY } & (3.7 \mathrm{M}) \\ \text { 1341 } & \text { B- } & \text { DECAY } & (52.6 \mathrm{M}) \\ \text { 133BA } & \text { EC } & \text { DECAY } & \\ \text { 214AT } & \text { A } & \text { DECAY } & \\ \text { 252CF } & \text { SF } & \text { DECAY } & \end{array}$

A half-life (in parentheses) may be added to specify the decaying nucleus completely. The decaying nucleus is identified by its standard NUCID (Section V.A).

Five decay types are recognized in the DSID field:

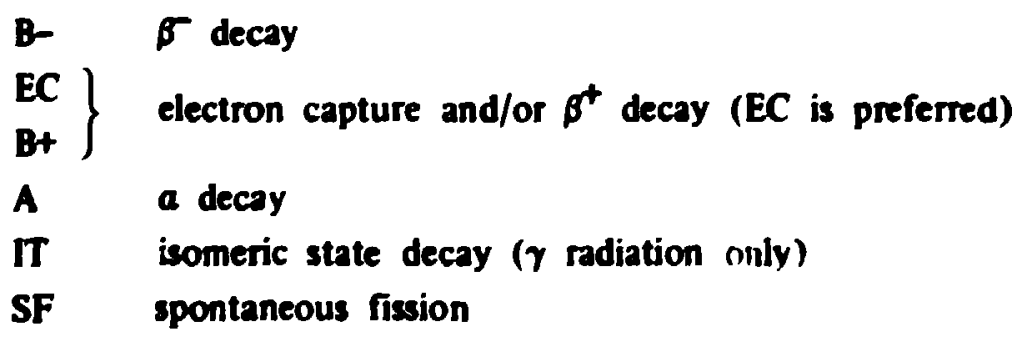


2. For a data set describine results of a nuclear reaction study, the DSID fiedd contains the troget and the incoming and outpoine perticles, secth as

\begin{tabular}{|c|c|}
\hline 20NE(P,D) & for $(p, d)$ \\
\hline $48 C A(A, A)$ & for $(a, a)$ \\
\hline IOSAC(4OAR,4OAR) & for $\left.\mathbf{P}^{\circ \bullet} \mathrm{Ar} .{ }^{\circ} \mathrm{Ar}\right)$ \\
\hline $\operatorname{sozR}(A, 4 N G)$ & for $(a, 4 m)$ \\
\hline $\begin{array}{l}45 S C(N, G), E=T H \\
C U I F X\end{array}$ & $\begin{array}{l}\text { for }(n, \gamma) \text {, therinal a } \\
\text { for Coulomb excitation }\end{array}$ \\
\hline
\end{tabular}

The tareel nuckeus and the reacting particte may be given in the standand form fsec NUCTD, Section V.A). (In rare cases, the anget mucleve, if not in its ground state, should be identified by its $T_{4 / 2}$ or $J$, in adition to its NUCID.) A reaction everis may be given when dexired or needed. The reactine perticles way siternatively be taken from the list of abbreviations:

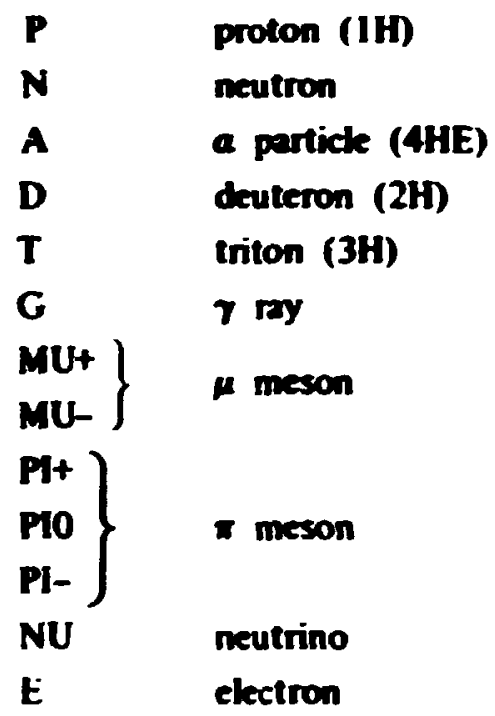

3. An ADOPTED data set contains the best representation of the present experimental knowledge about the levels of a nucleus and the $\boldsymbol{\gamma}$ branching. The data set will be named ADOPTED LEVELS or ADOPTED LEVELS, GAMMAS.

An ADOPTED data set contains a LEVEL recond for every level that has been reliably observed. GAMMA records may abo be included in an ADOPTED LEVELS data set. If GAMMA records are included, the name of the data set is ADOFTED LEVFIS, GAMMAS. If GAMMA records are not included, the name of the data set is ADOPTED LEVELS.

If all level information for a nucleus is contained in a data set for a single experiment. it is not necescary to make an additional ADOPTED data set as well. However, if more than one experimental data set contains level information about the nucleus. 
then a seperate ADOTTED data set MUST be made, even if the ADOPTED data set continis only the Q-VALUE record and a simple tround-state LEVEL record.

An ADOTTED deta set always contsins (in its IDENMFICATION record) a reference to the Nucter Date Sheets or simibre evoluation where the supporting data have bee compared. (This reference mary be entered automatically by the computer.)

As ADOrTED data set contriess a Q-VALUE record (e-2, as produced by the

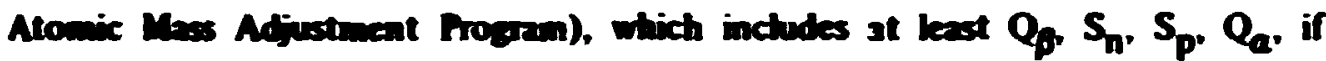
suibube.

\section{DSREF}

Refereaces to the man supportine pubtications or analyses are placed in this field by mens of standard Nuclear Data Project reference key numbers. If the data set describes a single mesourement, then the key number of the publistred report of the mesurement is sufficient. The DSREF freld may inctude up to three key numbers, each of which refers to a particular publication. Additional key numbers may be placed in COMMENT records.

D. RTYPE

RT rFE is a sinde-tetter code that gives a name to the RECORD type.

\begin{tabular}{ll} 
RTYPE & \multicolumn{1}{c}{ Description } \\
Blank & $\begin{array}{c}\text { May be IDENTIFICATION record, zeneral } \\
\text { COMMENT recori, or END record }\end{array}$ \\
N & NORMALIZATION record \\
P & PARENT record \\
Q & Q-VALUE record \\
L & LEVEL record \\
G & GAMMA record \\
B & B- record \\
E & EC (or EC + B+) record \\
A & ALPHA record
\end{tabular}




\section{UNCERTAINTIES}

Every experimental number entered into the data file should have an uncertainty associated with it, if at all possible. Uncertainties may be numeric or non-numeric. Numeric uncertainties may be symmetric or asymmetric.

\section{A. Standard Numeric Uitcertainties}

The "standard form" for expressing numeric uncertainties is as an integer (usually between 2 and 25 ) uncertainty in the leasi significant digit(s) of the experimental number; i.e., $448.7 \pm 0.7 \rightarrow 448.77 ; 0.3721 \pm 0.0014 \rightarrow 0.3721$ 14. The RTYPE for a standard uncertainty is usually formed by adding the prefix D to the RTYPE of the datum; e.g., E, DE; RI, DRI; MV, DMV.

An asymmetric uncertainty may be written in the standand form by including signs: $0.84_{-0.03}^{+0.10} \rightarrow 0.84+10-3$. The convention on asymmetric uncertainties is that they combine algebraically with the datum, such that $-3_{-4}^{+1}$ describes a range from -7 to -2 . (Asymmetric uncertainties are used frequently only in the DMR field.)

\section{B. Non-numeric Uncertainties}

The non-numeric uncertainties include the symbols for approximate. calculated. systematics, and also the relational operators such as greater than, less than or equal to. etc. The non-numeric uncertainty may be given either as a syinbol (if available) or as a two-letter code in the uncertainty field:

\begin{tabular}{|c|c|c|}
\hline Symbol & Letter code & Meaning \\
\hline$\approx$ & $\mathbf{A P}$ & approximately equal to \\
\hline$>$ & GT & greater than \\
\hline$>$ or $>=$ & GE & greater than or cqual to \\
\hline$<$ & LT & less than \\
\hline$<$ or $<=$ & LE & less than or equal to \\
\hline & SY & systematics \\
\hline & CA & calculated \\
\hline
\end{tabular}


vi. UNITS

A. Half-lives must include units. Use

$$
\begin{aligned}
& \text { FS }=10^{15} \mathrm{~s} \\
& \text { PS }=10^{12} \mathrm{~s} \\
& \mathbf{N S}=10^{-6} \mathrm{~s} \\
& \mathbf{U S} \equiv 10^{-6} \mathrm{~s} \\
& \mathbf{M S}=10^{-3} \mathrm{~s} \\
& \mathbf{S}=\text { second } \\
& \mathbf{M}=\text { minute } \\
& \mathbf{H}=\text { hour } \\
& \mathbf{D}=\text { day } \\
& \mathbf{Y}=\text { year } \\
& \mathbf{K Y}=10^{3} \mathrm{y} \\
& \mathbf{M Y}=10^{5} \mathrm{y} \\
& \mathbf{G Y}=10^{\circ} \mathbf{y} \\
& \mathbf{E V}=\text { width of level in } \mathrm{eV}
\end{aligned}
$$

Computer-standard exponential format may be used. Examples:

$$
\begin{aligned}
& \text { 3.7 PS }=3.7 E-12 \mathrm{~S} \\
& 4.21 \mathrm{GY}=4.21 \mathrm{E} \mathrm{Y}
\end{aligned}
$$

B. Intensity units are usually defined by the NORMALIZATION record (see Section III.B.4).

C. All energies are in keV unless specified otherwise.

D. Signs of certain experimental quantities (nuclear moments, Q-values, $\gamma$-mixing ratios) are as important as the numbers, themselves. If the sign is known, it should be given explicitly. (If the sign is not known, then the absence of any sign is just as descriptive as the +-.)

\section{FREE-FORM FIELDS}

A free-form field on any card is a region on the card where the input data values are self-descriptive; i.e., the field contains character strings such as EKC = 0.1045 or BE2 $<0.5$. The second, third, etc., cards for any record (when permitted) contain one free-form field between cols. 10-80 (see Section IV.B).

A free-form field contains character strings of the form:

(data type)(operator)(data value). 
The "data types" are restricted to the permitted names given under DTYPE" in Appendix I for the appropriate recond type. The "data value" is a numerical or characterstring value. A numerical data value may have an ascociated uncertainty (Section VI). The "operator" my be a mathematical symbol or its alphabetic representation.

$\begin{array}{ll}\text { EQ or }= & \text { equal to } \\ \text { LE } & \text { less than or equal to } \\ \text { LT or }< & \text { less than } \\ \text { GE } & \text { Ereater than } \\ \text { GT or }> & \text { Ereater than or equal to } \\ \text { AP } & \text { approximately equal to }\end{array}$

(The alphabetic representation must include at kest one Wank on each side; e.z., CEK_LT_27.4, but not CEK_LT27.4.) The character strings (data type + operetor + data value) may be separated from each other by one or more blanks. 


\section{ArrendDIX I \\ PREPARING FORMAT RECORDS}

\section{A. Introduction}

If the standand one-card formats described in Section III.B are used. then there is no need to include a FORMAT record. A FORMAT record is required if the data items in a one-and recond are too wide for the standard fields or if the data appear in an oxier differial from the standard recond of if data of a monstandard type are to be inctuded on the one-card record. (Use of the FORMAT records should be avoided whenever possible.t) Only the first cand of a record may have its organizcion dascribed by a FORMAT recond. Contimation cands for the record will always contrin their own format information (see Section IV.B). A FORMAT record may not be used for the IDENTIFICATION record, a COMMENT recond, the NORMALIZATION record, the Q-RECORD, the END recond, or another FORMAT record.

\section{B. Onenization of the FORMAT Recond}

The FORMAT record will always contain the letter " $F$ " in col. 7 and a character RTYPE (see Section V.D) in col. 8 to identify the type of record for which the format is being specified by the FORMAT recond. The FORMAT record consists of a single and for each record type for which a format is described. Continuation cands are not allowed. The text of the FORMAT record is contained in cols 10-80. The text consists of a series of equalities separated by commas or blanks: e.z. $E=10, D E=20, J=23, L=40$. In exneral, the form DTYPE $=$ COL in a FORMAT record implies that the data of type DTYPE are always contained in a field beginning in column COL of the RTYPE record. By implication, the field width includes all space up to the next langer value of COL given for some other data type DTYPE

If a FORMAT record is used, care must be taken to avoid conflicting format specifications. The same data type may not be identified with more than one location on the data record; i.e., $E=10, E=25$ is in error.

Since each field width is asamed to be the maximum available for the panticulas data type, it is important to specify the complefe format of the recond RTYPE. If the text of the FORMAT record for LEVEL records is $E=15, J=25, T=40$. then 10 card columns are allowed for E, 15 for J. and 41 columns are allowed for T.

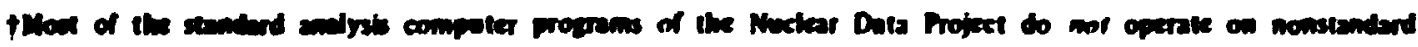
ate
} 


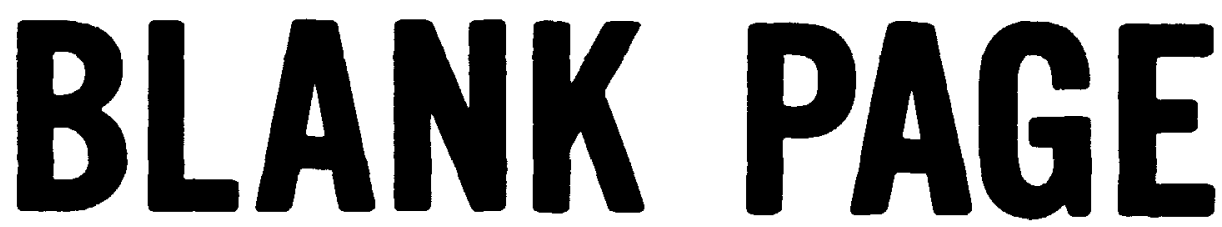


If any LEVEL record contains other information, e.g., the letter " $\mathrm{C}$ " for "unresolved doublet" in col. 77, then a strange value for the half-life $(T)$ will be inferred since the inforration is within the field defined for "T" type information.

C. Allowed Deta Types

Each record type is permitted to contain only a limited (but extendable) set of data types. For example, a GAMMA record is not allowed to contain information of data type DTYPE = J (nuclear spin). Neither may a LEVEL record contain LOGFT information. For each record type, the following table lists the data types permitted as of September 1977.

\section{The PARENT Record \\ 2. The Q-VALUE Record}

All allowed data types are included in the standard format description in Sections III.B.5 and III.B.6.

\section{The LEVEL Record}

Allowed data types, E, DE, J, T, DT, L, S, DS, C, MS, Q, are described with the standard formats in Section III.B.7. Additional allowed data types are:

\begin{tabular}{|c|c|}
\hline DTYPE & Description \\
\hline MV & Level energy in MeV \\
\hline DMV & "Standard" uncertainty in MV (Section VI) \\
\hline UEV, UKV, UMV & $\begin{array}{l}\text { Uncertainty in level enersy, expressed in eV, keV, and } \mathrm{MeV} \text {, } \\
\text { respectively }\end{array}$ \\
\hline PE & Percent uncertainty in level energy \\
\hline UE & $\begin{array}{l}\text { Uncertainty in level energy, given in same units as the level } \\
\text { energy itself }\end{array}$ \\
\hline $\begin{array}{l}\text { \%EC, \%SF, \%IT, \%B-, } \\
\% \mathrm{~B}+, \% \mathrm{~A}, \% \mathrm{P}, \% \mathrm{~N}\end{array}$ & $\begin{array}{l}\text { Percent jecay of the level by electron capture, spontaneous } \\
\text { fission, isomeric transition, or emission of a } \beta, \beta^{+}, a \text {, } \\
\text { proton, or neutron }\end{array}$ \\
\hline G & 8 -factor of the level \\
\hline $\begin{array}{l}\text { MOME1, MOME2, } \\
\text { MOMM1, MOMM2, } \\
\text { CONF }\end{array}$ & $\begin{array}{l}\text { Electric moments: dipole, quadrupole, ... } \\
\text { Magnetic moments: dipole, quadrupole, ... } \\
\text { Nuclear configuration of the level }\end{array}$ \\
\hline $\mathbf{F}$ & A "free-form" field (see Section VIII) \\
\hline BE1, BE2, ... & $\begin{array}{l}\text { Reduced electric transition probability (upward) given in units } \\
\left.e^{2} \times \text { (bams) }\right)^{L} \text {, where } L=1,2, \ldots \text { for the transition from } \\
\text { the ground state to this level }\end{array}$ \\
\hline ISPIN & \\
\hline
\end{tabular}


4. The GAMMA Record

Allowed data types, E, DE, RI. DRI, M, MR, DMR, CC, DCC, TI, DTI, C, ORG, END, Q, are described with the standard formats in Section III.B.8. Additional allowed data types are:

DTYPE
MV
DMV
UEV, UKV, UMV
PE
UE
BEI, BE2, ...
BEIW, BE2W, ...
BMI, BM2, ...
BMIW, BM2W, ...
CEK, CEL, CELI, ...
KC, LC, LIC, ...
EKC, ELC, ELIC, ...
K/L, M/L, LI/L2, ...
K/L, LT, ...
PRI, PTI
URI, UTI
F

Description

Gamma energy in MeV

"Standard" uncertainty in MV (Section VI)

Uncertainty in $\gamma$ enersy, expressed in $\mathrm{eV}, \operatorname{keV}$, and $\mathrm{MeV}$, resper tively

Percent uncertainty in $\boldsymbol{\gamma}$ energy

Uncertainty in $\gamma$ energy, given in same units as the $\gamma$ energy itself

Reduced electric transition probability (downward) given in units of $e^{2} \times$ (barns) $^{L}$, where $L=1,2, \ldots$

Reduced electric transition probability (downward) given in single-particle (Weisskopf) units

Reduced magnetic transition probability (downward) given in units of $\mu_{N}^{2} \times$ (barns) $^{L-1}$, where $L=1,2, \ldots$

Reduced magnetic transition protability (downward) given in single-particle (Weisskopf) units

Conversion-electron (ce) intensity fcr $K, L, L_{3}, \ldots$ conversion

Theoretical K-, L-, $L_{1}$-conversion ccefficient

Measured $K-$. L-, $L_{1}$-conversion coefficient

Conversion-electron intensity ratios

Ratio of $k, L, \ldots$ ce-intensity to total $(\gamma+c e)$ intensity

Percentage uncertainty in $\mathrm{KJ}, \mathrm{TJ}$

Uncertainty in $R I, T I$, given in same units as $R I, T I$

$A$ "free-form" field (see Scction Vill)

5. The B- Record

Allowed data types, E, DE, IB, DIB, LOGFT, DFT, COIN, UN, Q, are descr bed with the standard formats in Section III.B.9. Additional allowed data types are:

DTYPE Description

MV Beta energy in MeV

DMV "Standard" uncertainty in MV (Section VI)

UEV, UKV, UMV Uncertainty in $\beta$ energy, given in eV, $\mathrm{keV}, \mathrm{MeV}$, respectively

UE Uncertainty in $\mathcal{F}$ energy, given in same units as energy 
$\frac{\text { The B- Recoed }}{\text { Continued }}$

DTYPE

PE

EAV

F
Description

Percentage uncertainty in $\sigma$ enerby

Average enerzy of the $\sigma 5$ spectrum

$A$ "free-form" field (sec Section VIII)

6. The EC Record

Allowed data types, E, DE, IB, DIB, IE, DIE, LOGFT, DFT, TI, DT, COIN, UN, Q, are described with the standard formats in Section III.B.10. Additional allowed data types are:

\section{DTYPE}

MV

DMV

UEV, UKV, UMV

UE

FE

EAV

\section{Description}

Energy for electron capture to a kevel, given in MeV

"Standard" uncertainty in MV (Section VI)

Uncertainty in capture energy, given in eV, keV, MeV, respectively

Uncertainty in capture energy, given in same units as the enerzy itself

Percentage uncertainty in capture eneray

Average energy of the $\beta^{+}$spectrum

Fraction of decay by electron sapture from the $K, L, M$, $\mathrm{N}+\mathrm{O}+\ldots$ shells. (K, I, M, N + are also acceptable as DTYPE and have the same meaning)

$\mathbf{F}$

\section{The ALPHA Record}

All allowed data types are included in the standard format description in Section III.B.II. 


\section{ArrendiX 2 \\ COMPUTER FROGRANS}

The following Nuctear Data Project computer programs were desiened to operate or: data sets prepared in the standard format, as described in this manual. The fields required by the mose commonly used progams are described briefly below.

A. NDSLIST - Produces tables for publication in Nuclear Dece Streets.t

All the data records (except for the PARENT record) may be inctuded in the tables. Numeric data are usually listed in order of energy. General data set com:nents and record comments with blanks in coks 10-19 appear at the bead of the table. Flated comments appear as footnotes. Record comments appear as footnotes if they are placed at the head of the data set; they appear in the "comments" sectim of the table if they are placed immediately following a data record. Information on data continuation cards appears in the "comments" section (see examples in Appendix 3).

B. PLOT PROGRAM - Produces drawings for Nuclear Dita Sheets.

Data on continuation cards, comments, and numeric uncertainties (except for Q-cards) are iznored.

In general, levels are presented as horizontal straight lines, and radiations appear as arrows. All are drawn to scale. Question mark (?) in col. 80 produces dashed lines or arrows; $S$ in col. 80 produces dotted lines or arrows. Separation energies (SN, SP) on the Q-VALUE record appear as dotted lines. An "M" in col. 78 on the LEVEL record (for isomeric state) produces a heavy horizontal line. Ground states (0 or h!ank in cols. 10-19 of the LEVEL record) appear as heavy lines. Levels whose energies are not known relative to the ground state, but whose energies are known relative to each other, may be written for ENSDF as $x, x+270, x+750$, etc. These levels will be plotted at the scaled energy of the number contained in the energy field: i.e., $0,270,750$, etc.

Non-numeric uncertainties usually appear in the standard fashion; i.e., before the value. CA (for calculated) produces parentheses around the corresponding number. SY produces the word "SYST" on Q-value uncertainties.

$Q^{-}$on the Q-VALUE record in adopted levels data sets is used to plot to scale the g.s. levels of different nuclides of a mass-chain.

tNucker Dase sheers (1973-present). Academic Press, Inc., New York and London. 
For ploting reaction data sets, if $L$ is given for ay level, then $L$ and $S$ are plotted for all levels, unlas $J$ is explicitly requested.

In plotting EC (electron capture) information, E, IB, IE, and LOGFT are plotted: TI is ipoced.

In plotion GAMMA reconts, MR is abrys igored. Severd options are avaibble for presentiog enana trasition intensities (such as relative photon intensities, relative

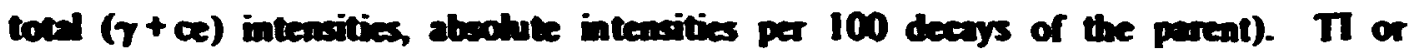
RI ax CC fields on the GAMMA record and BR and NR or NT felds on the NORMALZATION recond are used for the calculations. (The correspondias uncertaintios are used for rounding-of.)

The letter "C" in cols $78-79$ (on GAMMA records) produces "coincidence dots" on panama arrows. A "C" in col. 77 (on ALFH, B-, and EC records) produces a coivicidence dot (on end of anow) for $a, \beta$, $\in$ arrous (see example in Appendix 3).

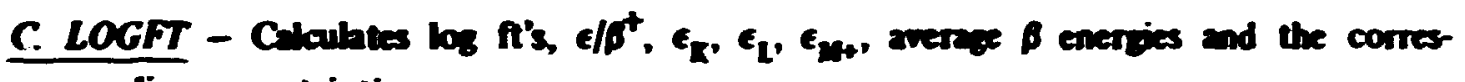
ponding uncertaintias.

The following frelds are used for the calculations: E, DE, T, DT, QP, DQP, of the PARENT record; $\Pi, D T, U N$ in the EC and $\mathrm{B}$ - reconds (if $\mathrm{T}$ is blank on the EC record, then IB + IE is used instead); E and DE in the LEVEL record of the danghter mucleas; BR, NB in the NORMALIZATION record (if NB is left blank, TI or IB + IE is acoumed to be in $\%$ of parent decays).

D. ALPHA HF - Calculates a-decay hindrance factors.

The fields used ar NUCID, E, T, QP of the PARFNT record: E of the LEVEL record; IA of the ALPHA record; BR of the NORMALIZATION record. For cdd-A and odd-odd nuclei, the redius parameter has to be given on a record type coniment at the head of the data set; for example,

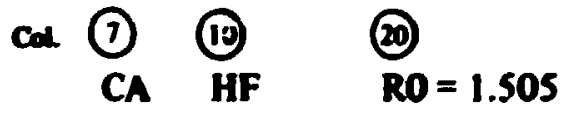

E GTOL (Gamma to Level) - Calculates "beat" level enengies by least-squares adjustment (taking account of recoil correction), as well as the intensity bulance at each level. Adjucted leved energies are ued to calculate r-roy eneries; discrepances with input are naceed.

The following fields are used: E, DE, RI, DRI, CC, DCC, TI, DTI, Q on GAMMA records of placed ammes. Questionably placed eamms ("p" in col. 80) and nonnumeric uncertaintie are ignored in the calculations. 
F. HSICC (Intermal Conrersion) - Calculates CC (total conversion coefficient) and other comrersion coefficients.

Fields used are E (M, MR, DMR if known) in the GAMMA record; NUCID in the ID record.

G. MEDLIST (Mediced Application List) - Calculates K. L X-ray intensities and Auget conversion-electron redintions.

Fields used are E, DE, RI, DRI, $I I$ on first GAMMA cand; KC, LC, MC+, $K / T, L / T$ on second GAMMA cands; IB, IE, $T$ on first $B-$ and $E C$ cards; $C K, C L$, $C M+(K, L$ and $M+$, respectively, are also acceptable and hrve the same meaning) on second EC cands; EAV on second B- and EC cards; NR, BR, NB on NORMALIZATION record. 


\title{
APPENDIX 3
}

\section{SAMPLE DATA SET INRUT/OUTTUT}

\author{
A. ENSDF Input
}

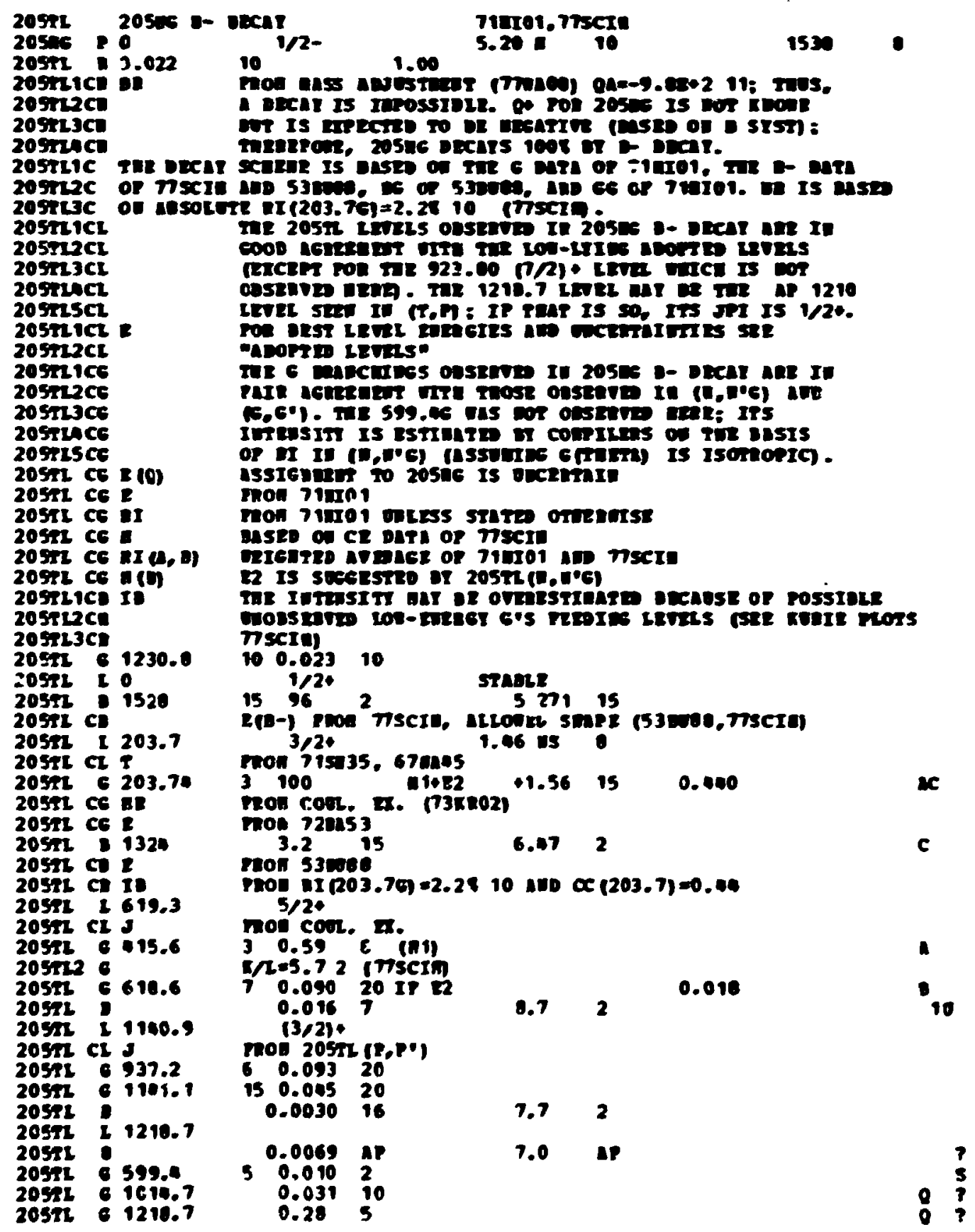


B. NDSLIST Ontpat

man an seres

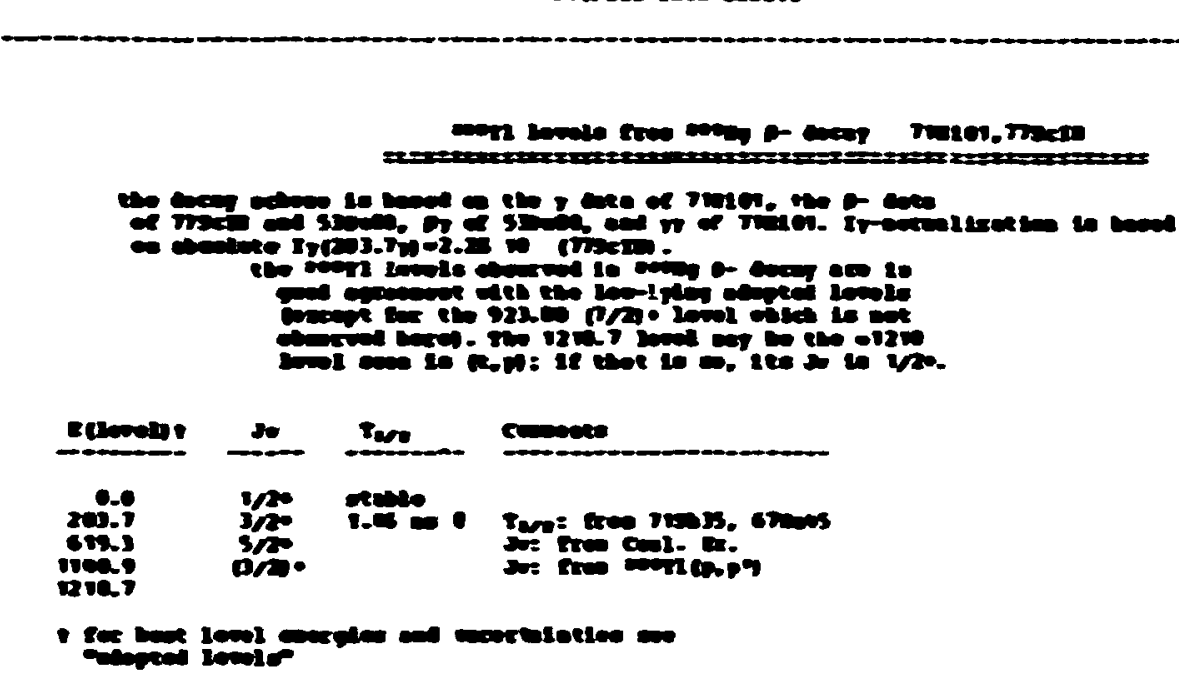

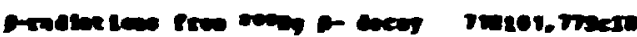

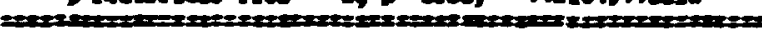

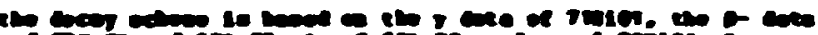

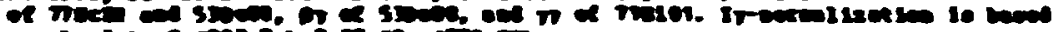

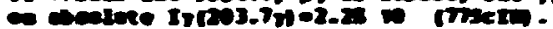

int

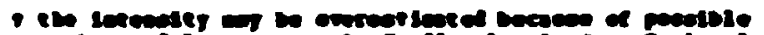

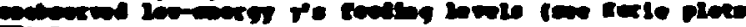
There

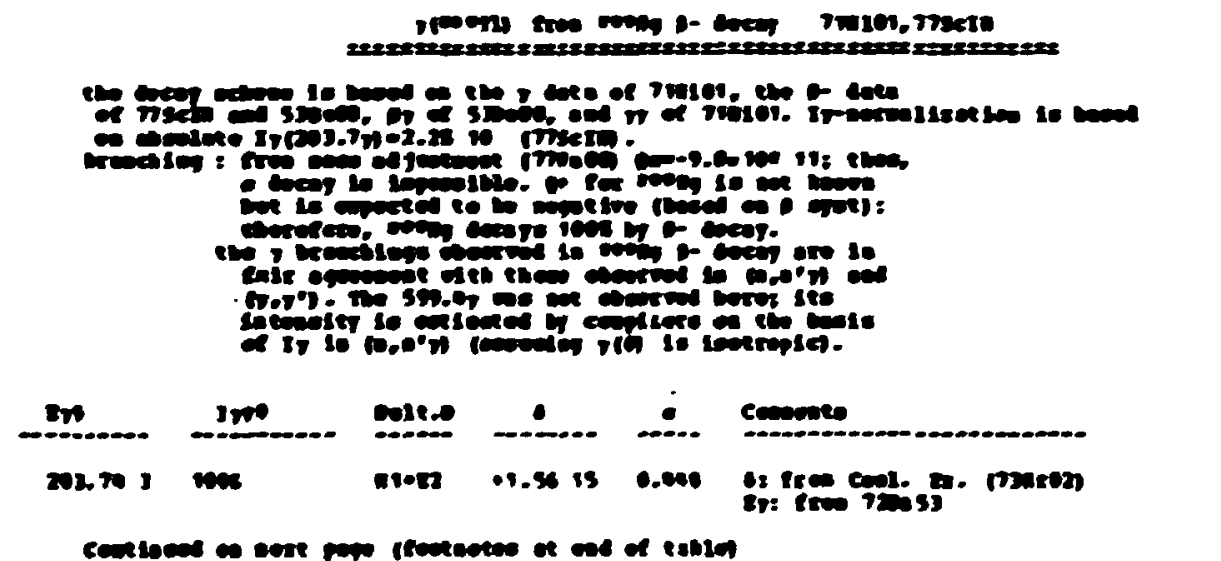




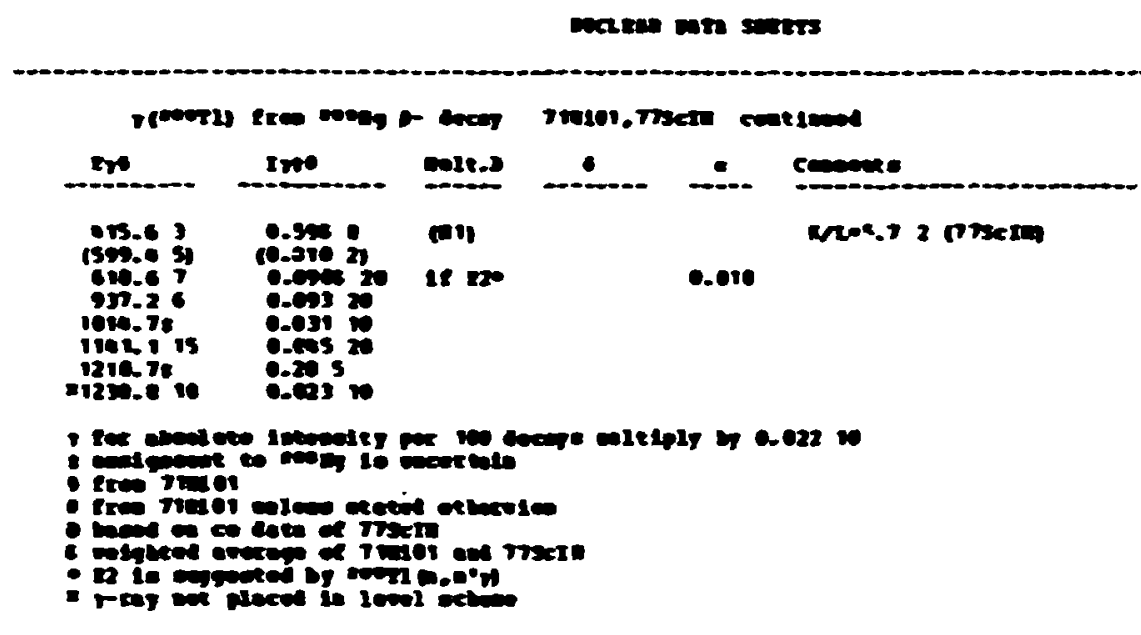

C. PLOT Output

205ig B- Decr

7htod. Tricen

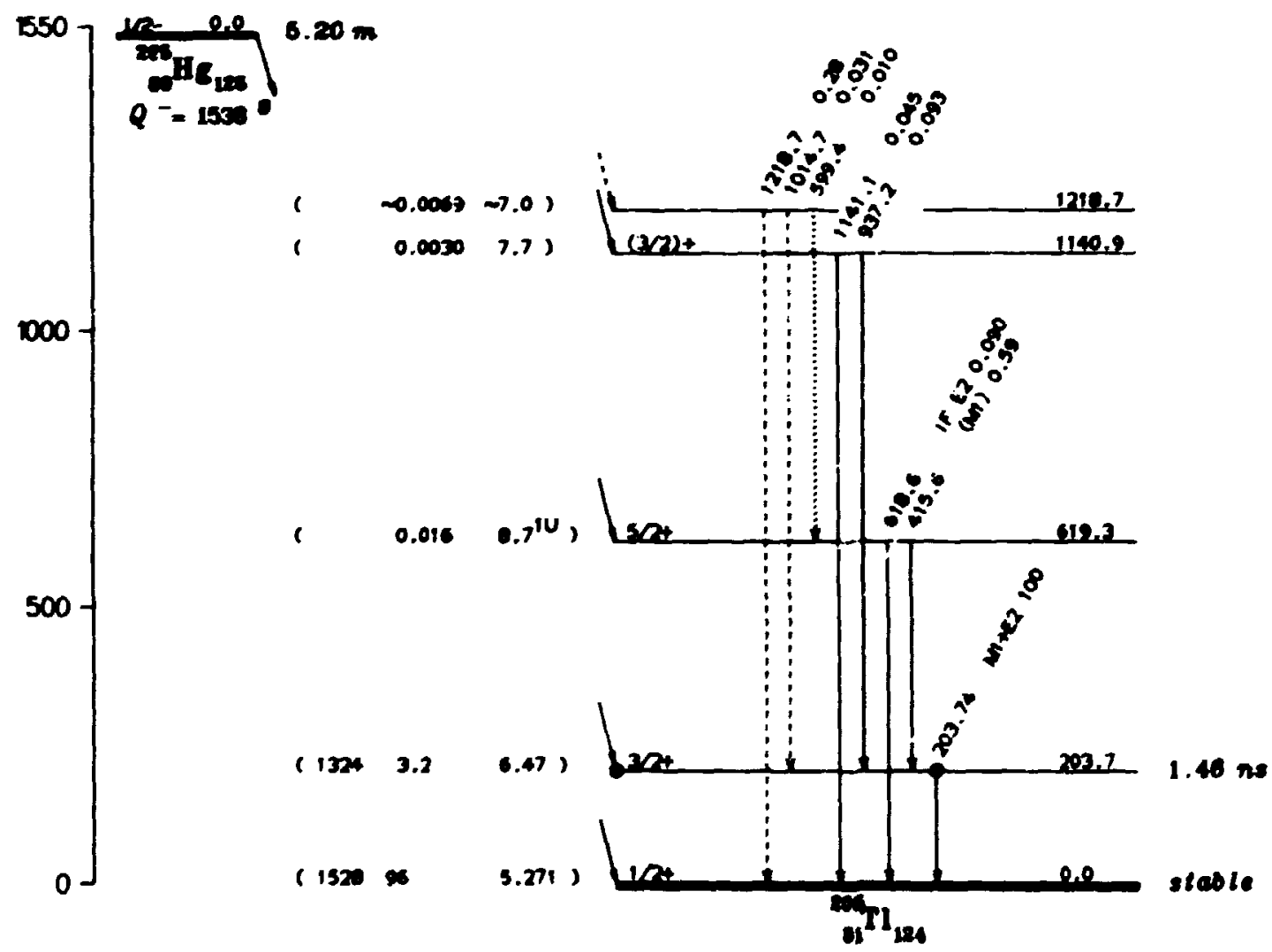




\title{
ATrENDIX 4
}

\section{NDSUST TRANSLATION DICTIONARY}

The NDSLIST program (see Appendix 2) transhates the text of comments (CTEXT in Section 11.B.3) from th: computer-readable ENSDF input into printed output for Nuclear Data Sheets.

The punched card input of the standard EBCDIC characters is shown below. (For example, an IBM 029 keypunch machine built to U.S.A. specifications uses this standard convention.)

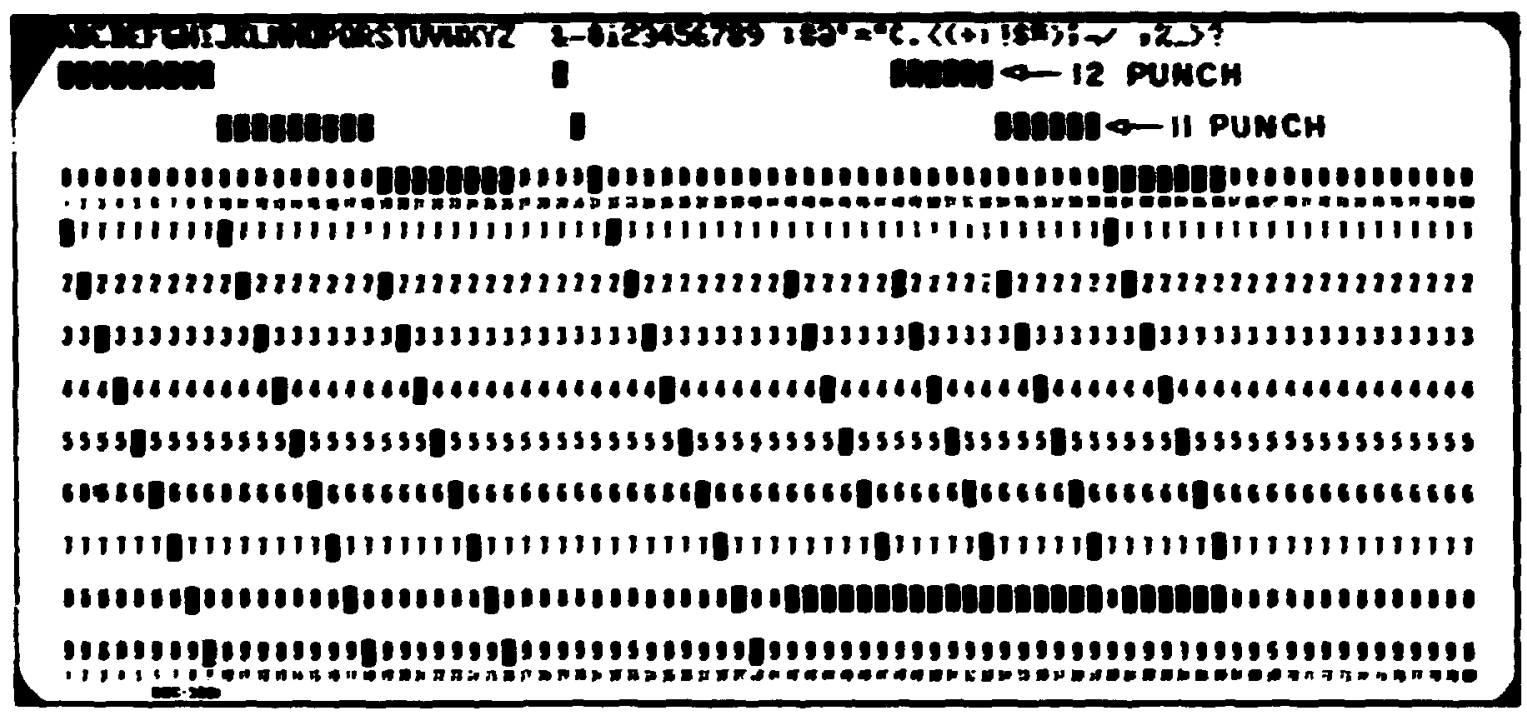

A sample of the translation dictionary, as of October 1977, is shown below. The dictionary is constantly enlarged and improved as new needs are encountered. The sample is arranged in the following order.

\author{
Engdish Alphabet \\ Greek Alphabet \\ Mathematics \\ Isotoper: \\ Proper Names \\ Key Numbers \\ Configurations
}


 \\ BLANK PAGE \\ B}


ourae are sidus

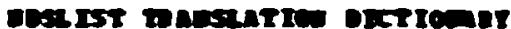

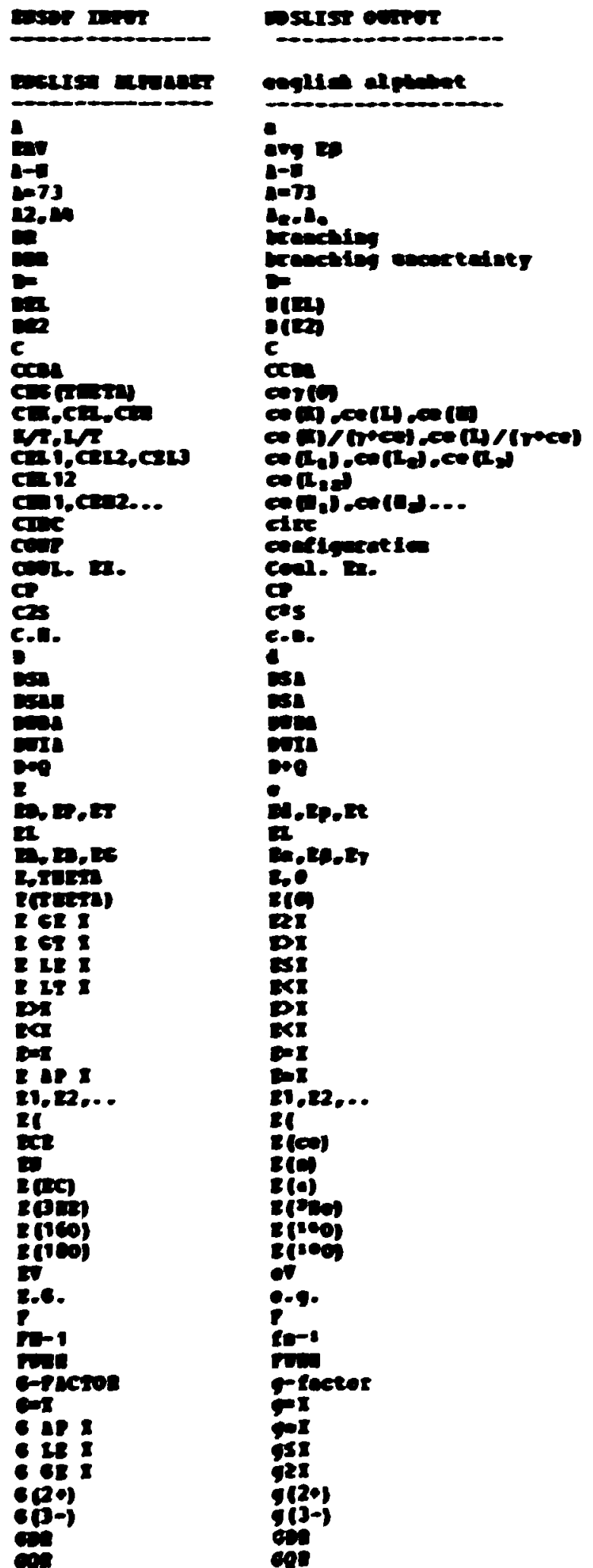

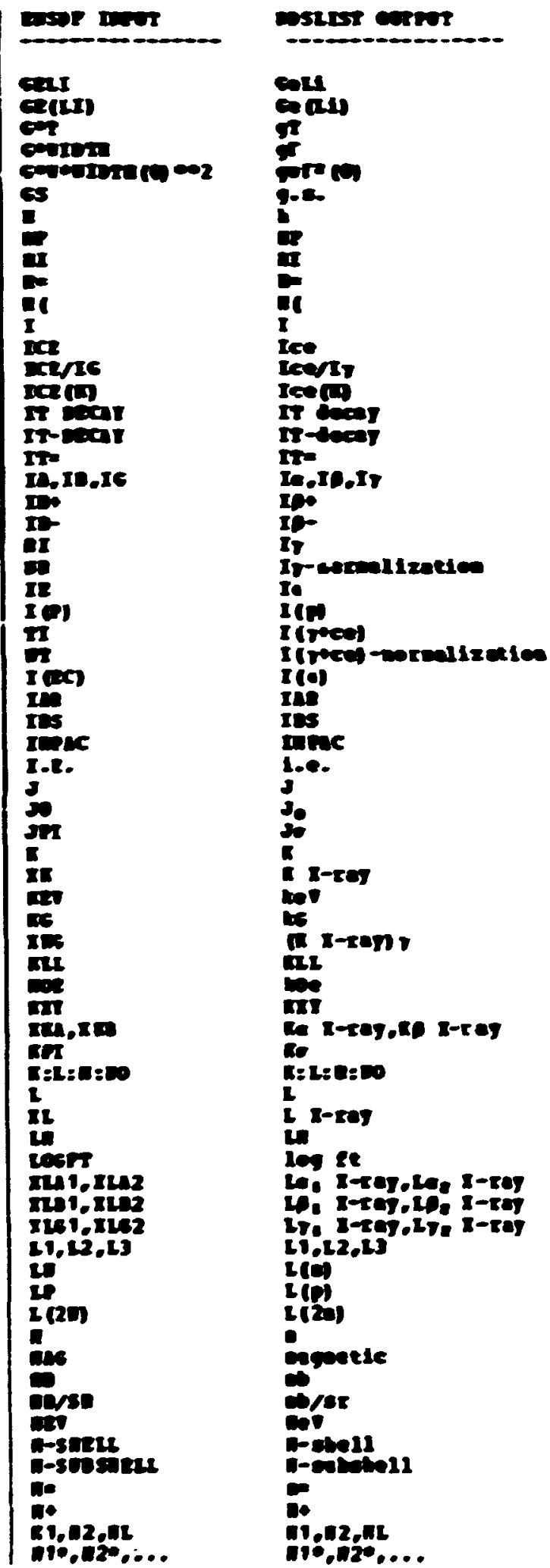




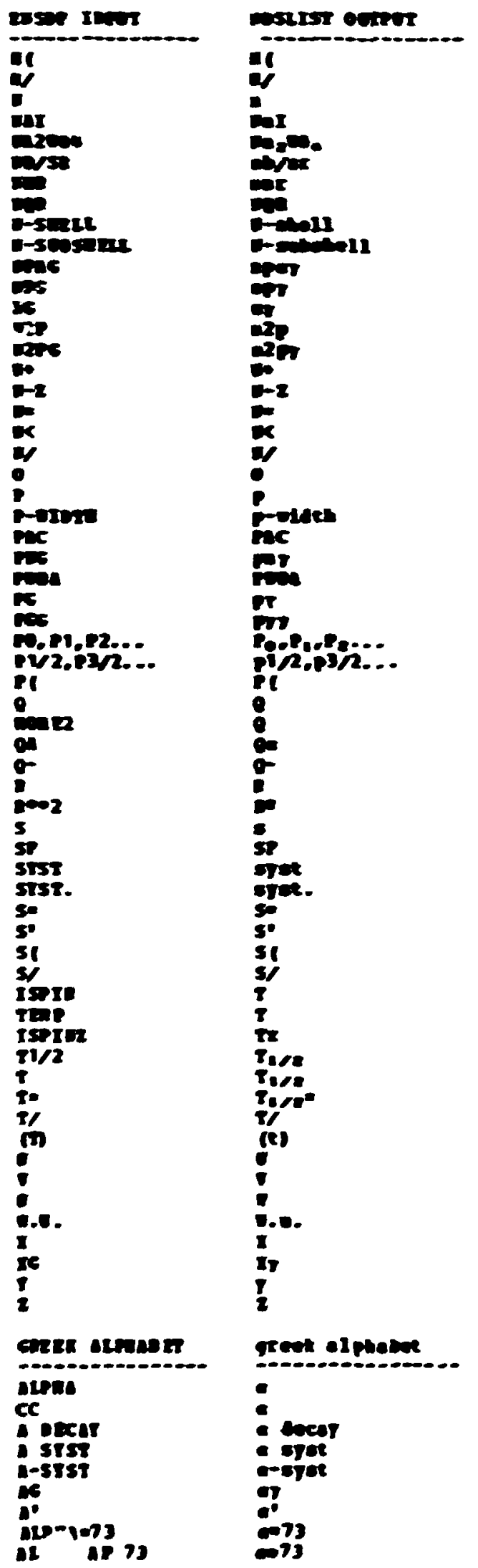

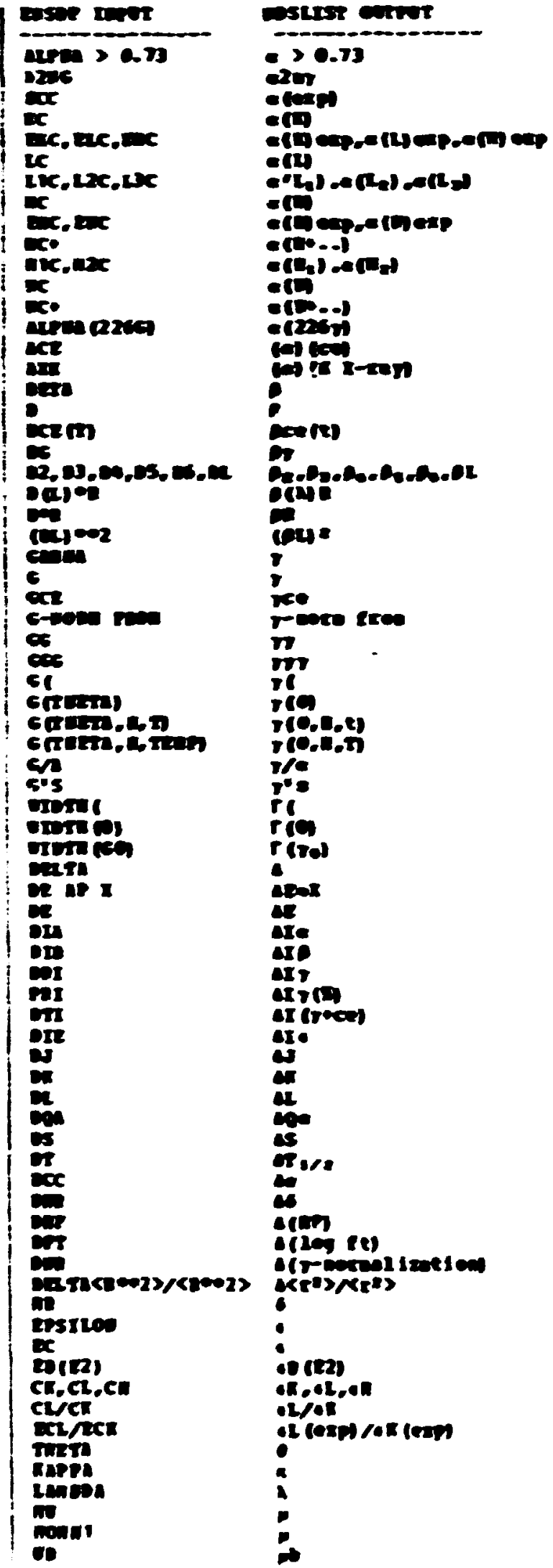




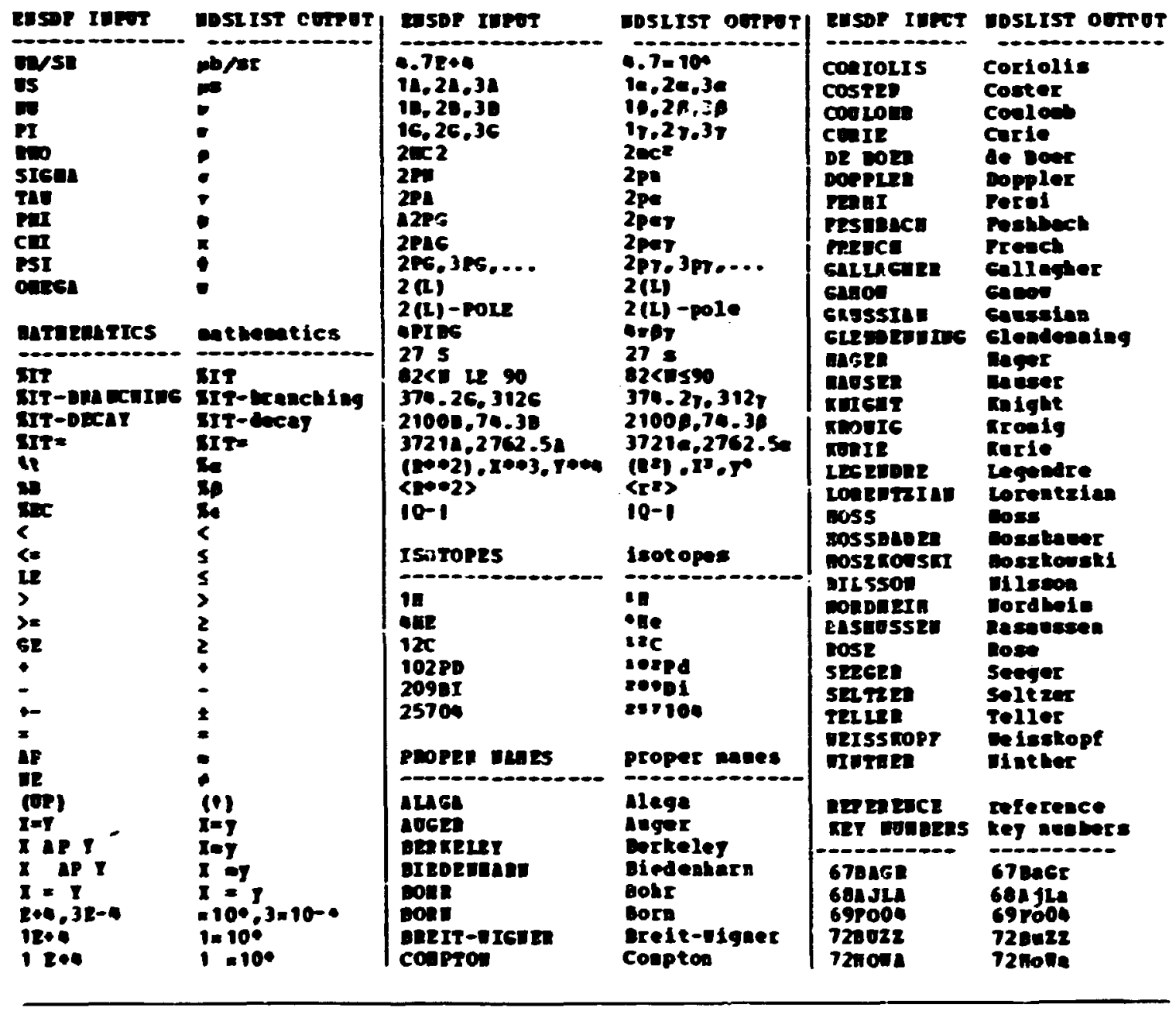

ENSPR INTHT

-

conpigenarions

conte (1.,IL)

conte (1), It. -1$)$

сCST= (1.,109/2)

contra (1), 33\% $\% 2,+3,23 / 2-1$

cons $=(1,3 P 1 / 2,-1)$

cowre $=((200) 3-)(1, \pi, 0,+4, d)) \mathrm{J}$

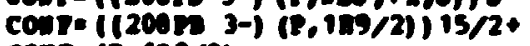

cosre $(1,109 / 2)$

coste $(18,1109 / 2,+2,04)(10,2) 3 / 2,-3,11 / 2$

cotr $=\left(1,30^{\circ} ?,+3,23 / 2-\right)$
WDSLIST OOTPHT

Configaratioas

conflgeret lone (o al $)$

configeretione $(0 \text { al } j)^{-1}$

conflgerat ion= $(0$ ig,

configuration= (o $390 / 1)+0_{2} / 2-$

conelgeratione (o $3 p_{2}(p)-s$

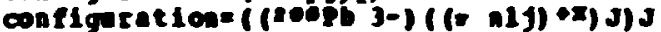

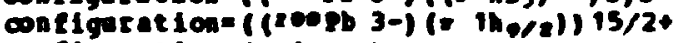

conelgaration= (o $190 / 2)$

$2-1125 / 2-$

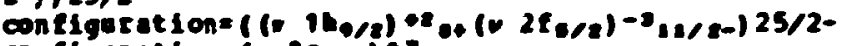

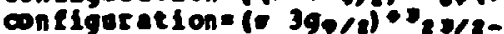

